
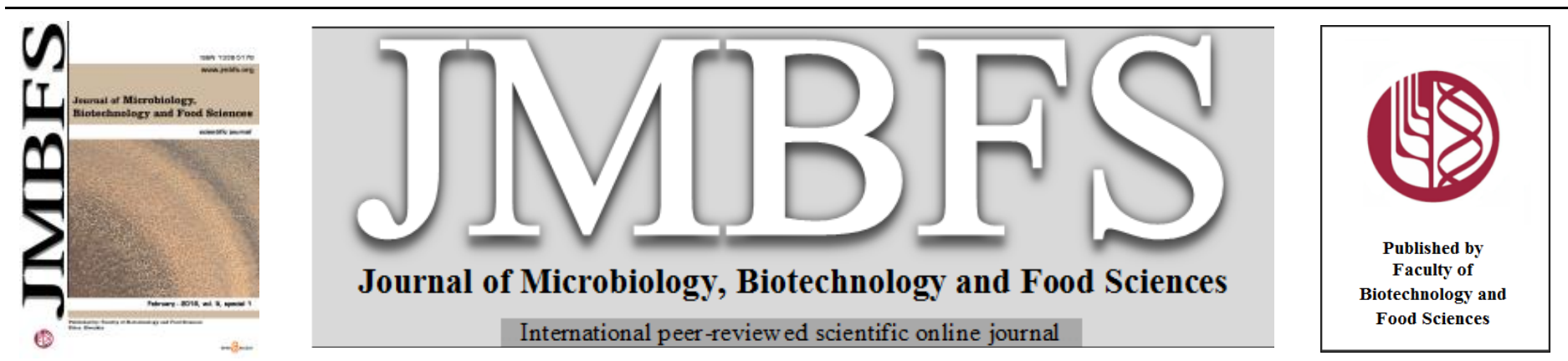

\title{
DO PUNICALAGINS HAVE POSSIBLE IMPACT ON SECRETION OF STEROID HORMONES BY PORCINE OVARIAN GRANULOSA CELLS?
}

\author{
Dagmara Packová, Adriana Kolesárová \\ Address(es): Ing. Dagmara Packová, \\ ${ }^{1}$ Slovak University of Agriculture, Faculty of Biotechnology and Food Sciences, Department of Animal Physiology, Tr. A. Hlinku 2, 94976 Nitra, Slovak Republic.
}

*Corresponding author: xpackovad@is.uniag.sk

doi: 10.15414/jmbfs.2016.5.special1.57-59

\section{ARTICLE INFO}

Received 4. 12. 2015

Revised 7. 1. 2016

Accepted 15. 1. 2016

Published 8. 2. 2016

Regular article

open $\mathcal{O}$ access

\begin{abstract}
Punicalagin is a major component responsible for pomegranate's antioxidant properties. Punicalagin is the predominant ellagitannin of Punica granatum and present in two isomeric forms; punicalagin $\alpha$ and $\beta$. Punicalagins are metabolised to ellagic acid (antioxidant) and microorganisms present in colon can metabolize ellagic acid to urolithins - each other substances could be responsible for effect on cell intracellular mechanism. The aim of our study was to observe the effect of punicalagins on secretion of steroids hormones progesterone and $17 \beta$-estradiol. Ovarian granulosa cells were cultivated during $24 \mathrm{~h}$ without (control group) and with various doses $\left(0.01,0.1,1,10\right.$ and $\left.100 \mu \mathrm{g} \cdot \mathrm{ml}^{-1}\right)$ of pomegranate compounds - punicalagins. Steroid hormones progesterone and $17 \beta$-estradiol were evaluated by ELISA. Obtained results showed that the secretion of progesterone and 17 $\beta$-estradiol by ovarian granulosa cells was not significantly $(\mathrm{P} \geq 0.05)$ influenced by punicalagins. In this pilot study no effects of punicalagins on porcine ovarian granulosa cells were found.
\end{abstract}

Keywords: Progesterone, 17 $\beta$-estradiol, granulosa cells, punicalagins, steroidogenesis

\section{INTRODUCTION}

Punicalagins are ellagitannins in which gallagic and ellagic acid are linked to a glucose molecule (Cerdá et al. 2003). Punicalagin has two isomeric forms in pomegranate: $\alpha$ and $\beta$. Chemical name of punicalagin is 2,3-(S)hexahydroxydiphenoyl-4,6-(S,S)-gallagyl-D-glucose (Tyagi et al. 2012). Punicalagins are phenolic compounds which are responsible for the main antioxidant activity of pomegranate (Punica granatum, Punicaceae) (Syed $\boldsymbol{e t}$ al. 2007). Punicalagin levels are widely variable in pomegranate juice and can range from as low as $0.014-1.5 \mathrm{~g} .1^{-1}$ depending on the fruit cultivar as well as processing and storage conditions (Syed et al. 2007). Pomegranate peels and pulps have a higher total phenolic and antioxidant activity than juice (Gözlekci et al. 2011; Elfalleh et al. 2011).

Punicalagin is a large molecule and knowledge about the fate of ellagitannins (include punicalagins) in human or animals is very sparse. In a recent study by Cerdá et al. (2003) the metabolism of punicalagins was described in rat. Punicalagins or metabolites of punicalagins were detected in faeces, urine and plasma. Native punicalagins were identified in plasma and urine, but at a very low concentration. The main metabolites present in biological fluids are those derived from punicalagins by hydrolysis and future conjugation. Rat microflora is able to metabolise ellagic acid derivatives to produce $6 \mathrm{H}$-dibenzo[b,d]pyran-6onemetabolites (urolithins) (Cerdá et al. 2003). Punicalagins were metabolized and/or absorbed. This means that most of the ingested punicalagins have to be transformed to known (punicalin, ellagic acid, gallagic acid) or unknown metabolites or accumulated in tissue (Cerdá et al. 2003). This in vitro study was focused on the secretion of steroid hormones, progesterone and $17 \beta$-estradiol, by porcine ovarian granulosa cells after punicalagin administration.

\section{MATERIAL AND METHODS}

\section{Material}

Ovaries ( $n=12$ per experiment) of Slovakian White gilts were obtained from healthy animals without visible abnormalities. All experimental animals are kept under standard conditions at slaughterhouse in Myjava. Ovaries were transported to the laboratory at $4^{\circ} \mathrm{C}$ and washed in sterile physiological solution.

\section{Isolation of granulosa cells}

Ovarian granulosa cells were used in this in vitro study. The suspension of the cells was centrifuged for $10 \mathrm{~min}$ at $200 \mathrm{xg}$ (to divide the follicular liquid from granulosa cells), washed in sterile DMEM/F12 1:1 medium with $10 \%$ fetal bovine serum and $1 \%$ antibiotic-antimycotic solution. The washing was repeated two or three times as needed. Viability of cells was determined using trypan blue. Ovarian cells were divided into and cultured in 24-well culture plates. The well plates were incubated at $37.5{ }^{\circ} \mathrm{C}$ and $5 \% \mathrm{CO}_{2}$ in humidified air until a $75 \%$ confluent monolayer ( 5 days). At this point, the medium ( $1 \mathrm{ml}$ per well) was removed and ovarian cells were incubated in a fresh medium with $10 \%$ fetal bovine serum, $1 \%$ antibiotic-antimycotic solution and without (control group) or with punicalagins (Sigma Aldrich, St. Louis, MO, USA) at 0.01, 0.1, 1, 10, 100 $\mu \mathrm{g} . \mathrm{ml}^{-1}$. The cultures were kept for $24 \mathrm{~h}$. Following cultivation the media were aspirated from the well plates and analysed for steroids hormones.

\section{Viability of granulosa cells}

Viability of granulosa cells was assessed by trypan blue solution (0.4\%). A reference sample $(500 \mu \mathrm{l})$ was detracted from cell suspension. Trypan blue was added $(100 \mu \mathrm{l})$ into the test tube with suspension in a ratio of $5: 1$. The suspension with trypan blues was gently mixed and incubated $5 \mathrm{~min}$ at room temperature. The total cells, vital and death cells were accounted using a haemocytometer from minimum 10 fields and the percentage of vital cells was assessed using a formula (vital cells/total cellsx100\%).

\section{ELISA (Enzyme-linked immunosorbent assay)}

Quantification of hormones (progesterone and 17 $\beta$-estradiol) was performed after exposure of punicalagins by enzyme linked immunosorbent assay (ELISA). The principle of this colorimetric method is a series of competitive reactions between antigens (hormones) in the sample with horseradish enzyme-labelled antigen for binding to the limited number of antibody sites within a 96-well microplate (Grainer, Germany). ELISA assays (Dialab, Wiener Neudorf, Austria) were performed according to the manufacturer's instructions. After $1 \mathrm{~h}$ incubation (37 ${ }^{\circ} \mathrm{C}, 95 \%$ air atmosphere, $5 \% \mathrm{CO}_{2}$ ) the bound/free separation was performed by a simple solid-phase washing. The enzyme substrate $\left(\mathrm{H}_{2} \mathrm{O}_{2}\right)$ and the TMBSubstrate were added. After the appropriate time was elapsed for maximum colour development, the enzyme reaction was stopped and the absorbancies were 
determined. Hormone concentration in the sample was calculated based on a series of calibrators. The colour intensity was inversely proportional to the hormone concentration in the sample. The absorbance was determined at a wavelength $450 \mathrm{~nm}$ using a microplate ELISA reader (Thermo Scientific Multiskan FC, Vantaa, Finland). The results were evaluated by One Way ANOVA. Intra- and inter-assay coefficients for progesterone were $\leq 4 \%$ and $\leq 9.3$ $\%$. For $17 \beta$-estradiol intra- and inter-assay coefficients were $\leq 9 \%$ and $\leq 10 \%$. Sensitiveness for progesterone was $0.05 \mathrm{ng} \cdot \mathrm{ml}^{-1}$ and $8.68 \mathrm{pg} \cdot \mathrm{ml}^{-1}$ for $17 \beta$ estradiol..

\section{RESULTS AND DISCUSSION}

In our previous in vitro study punicalagins were described as a possible effector in the processes of ovarian steroidogenesis (Packová et al., 2015). Nagata et al. (2007) have shown that pomegranate juice is a potent inhibitor of CYP2C9 and CYP3A enzymes - these enzymes belong to cytochrome p450 group; and are responsible for cholesterol, steroid and lipid metabolism or synthesis. This study was focused on steroid hormones and the influence of punicalagins on the secretion of steroid hormones - progesterone and 17 $\beta$-estradiol. Fig.1 describes the secretion of progesterone as the first important hormone of steroid synthesis. Punicalagin had no significant $(\mathrm{P} \geq 0.05)$ impact on secretion of progesterone Similarly, Ming et al. (2014) described a significantly decreased progesterone in the samples (prostate cancer cell lines - 22RV1 and LNCaP) treated with pomegranate extracts. However in our previous study, punicalagin at $100 \mu \mathrm{g} . \mathrm{ml}^{-1}$ increased the progesterone secretion by rabbit ovarian cells (Packová et al., 2015)

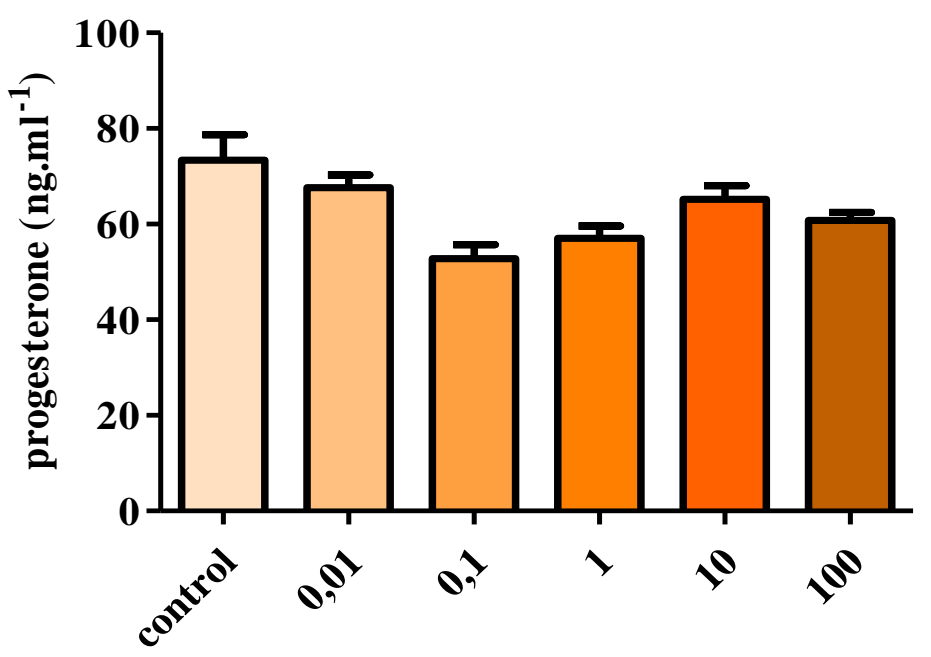

doses of punicalagin $\left(\mu \mathrm{g} \cdot \mathrm{ml}^{-1}\right)$

Figure 1 Effect of punicalagins $\left(\mu \mathrm{g} . \mathrm{ml}^{-1}\right)$ on progesterone $\left(\mathrm{ng} \cdot \mathrm{ml}^{-1}\right)$ secretion by porcine ovarian granulosa cells. Non-significant $(\mathrm{P} \geq 0.05)$ differences among the control and experimental groups. The results were evaluated by One Way ANOVA.

The polyphenol from fermented pomegranate juice, pericarp and oil were shown to affect a blockade of endogenous active estrogen biosynthesis with subsequent inhibition of aromatase activity (Toi et al. 2003). Fig. 2 shows secretion of $17 \beta$ estradiol by porcine ovarian granulosa cells after application of different doses of punicalagin, but these results were not significant $(\mathrm{P} \geq 0.05)$. Recently, Ming et al. (2014) used pomegranate extracts on prostate cancer cells to suggest that steroid biosynthesis might favour the backdoor pathway over the classical $\Delta 4$ and $\Delta 5$ pathways. They described the effect of pomegranate extract on androgen biosynthesis pathways specifically using two prostate cancer cell lines and prostate cancer mouse model. According to our previous study punicalagins like mainly ellagitannins of pomegranate, had influence on secretion of $17 \beta$ estradiol. Punicalagins at $10 \mu \mathrm{g} \cdot \mathrm{ml}^{-1}$ significantly $(\mathrm{P}<0.005)$ reduced the secretion of $17 \beta$-estradiol by rabbit ovarian fragments (Packová et al., 2015). Using lyophilized fresh pomegranate juice, Kim et al. (2002) reported that phenols from pomegranate inhibit $55 \%$ estrogen activity by normal human breas epithelial cells. Punicalagins or its derivatives (ellagic acid etc.) might have a possible effect on the process of ovarian steroidogenesis (Packová et al. 2015). Hong et al. (2008) showed that pomegranate protectants (polyphenols) may be effective against prostate cancer by down regulation of genes involved in androgen synthesis. Crushed and dried seed produce oil with $80 \%$ punicic acid, the 18-carbon fatty acid, along with isoflavone genistein, the phytoestrogen coumestrol and the sex steroid estrone (Syed et al. 2007).

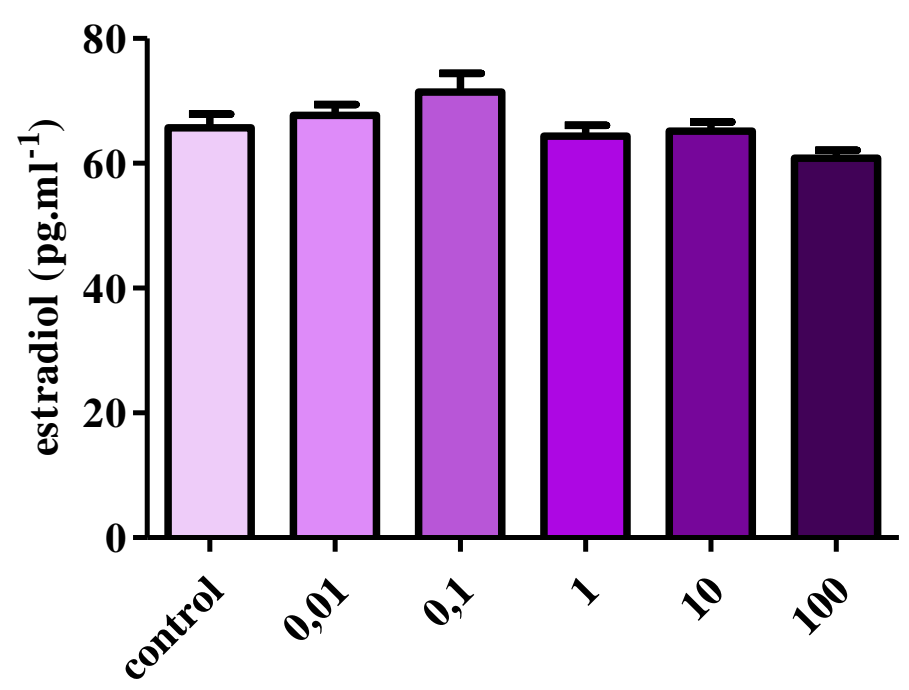

doses of punicalagin $\left(\mu \mathrm{g} \cdot \mathrm{ml}^{-1}\right)$

Figure 2 Effect of punicalagin $\left(\mu \mathrm{g} \cdot \mathrm{ml}^{-1}\right)$ on $17 \beta$-estradiol $\left(\mathrm{pg} \cdot \mathrm{ml}^{-1}\right)$ secretion by porcine ovarian granulosa cells. Non-significant $(\mathrm{P} \geq 0.05)$ differences among the control and experimental groups. The results were evaluated by One Way ANOVA test.

\section{CONCLUSION}

The research was focused on possible effects of punicalagins on porcine ovarian granulosa cells. Punicalagins or its derivatives (ellagic acid etc.), which were used in the present study might have no effect on steroidogenesis by porcine ovarian granulosa cells, but our previous studies with rabbit ovarian fragments have shown that punicalagin affects thesecretion of steroid hormones (progesterone and $17 \beta$-estradiol). Further research is necessary for a complex conclusion. There are more questions related to the effect of punicalagins or compounds from pomegranate on regulation of ovarian cells.

Acknowledgments: This work was financially supported by the Ministry of Education, Science, Research and Sport of the Slovak Republic project no. 1/0022/13, APVV-0304-12, European Community under project no 26220220180: Building Research Centre „AgroBioTech"

\section{REFERENCES}

Cerdá, B., Llorach, R., Cerón, J. J., Espín, J. C., Tomás-Barberán, F. A. (2003) Evaluation of the bioavailability and metabolism in the rat of punicalagin, an antioxdant polyphenol from pomegranate juice. European Journal of Nutrition 42(1), 18-28. http://dx.doi.org/10.1007/s00394-003-0396-4 Elfalleh, N., Tlili, N., Nasri, N. Yahia, Y., Hannachi, H., Chaira, N., Ying M., Ferchichi, A. (2011). Antioxidant Capacities of Phenolic Compounds and Tocopherols from Tunisian Pomegranate (Punica granatum) Fruits. Journal of Food Science, 76(5), 707-713. http://dx.doi.org/10.1111/j.1750-3841.2011.02179.x

Gözlekci, S., Saracoglu, O., Onursal, E., Özgen, M. (2011). Total phenolic distribution of juice, peel, and seed extract of four pomegranate cultivars. Pharmacognosy Magazine, 7(26), 161-164. http://dx.doi.org/10.4103/09731296.80681

Kim, S., Liu, Y., Gaber, M. W., Bumgardner, J. D., Haggard, W. O., Yang, Y. (2009) Development of chitosan-ellagic acid films as a local drug delivery system to induce apoptotic death of human melanoma cells. Journal of Biomedical Materials Research, 90(1), $145 \quad-\quad 155$ http://dx.doi.org/10.1002/jbm.b.31266

Ming, D.S., Pham, S., Deb, S., Chin, M. Y., Kharmate, G., Adomat, H., Beheshti, E. H., Locke, J., Guns, E. T. (2014). Pomegranate extract impact the androgen biosynthesis pathways in prostate cancer models in vitro and in vivo. Journal of Steroid Biochemistry and Molecular Biology, 143, 19-28 http://dx.doi.org/10.1016/j.jsbmb.2014.02.006

Nagata, M., Hidaka, M., Sekiya, H., Kawano, Y., Yamasaki, K., Okumura, M., Arimori, K. 2007. Effects of pomegranate juice on human cytochrome p450 2C9 and tolbutamide pharmacokinetics in rats. Drug metabolism and Disposition, 35, 302-305. http://dx.doi.org/10.1124/dmd.106.011718

Packova, D., Carbonell-Barrachina, A. A., Kolesarova, A. (2015) Ellagitannins Compounds From Pomegranate as Possible Effector in Steroidogenesis of Rabbit Ovaries, Physiological research, 64, 583-585.

Syed D. N., Afaq, F., Mukhtar, H. (2007). Pomegranate derived products for cancer chemoprevention. Seminars in Cancer Biology, 17, 377-385. http://dx.doi.org/10.1016/j.semcancer.2007.05.004 
Taygi, S., Singh, A., Bhardwaj, P., Sahu, S., Yadav, A. P., Kori, M. L. (2012). Punicalgins-A Large Polyphenol Compounds Found in Pomegranates:

A Therapeutic Review. Journal of Plant Sciences, 5(2), 45-49.

Toi, M., Bando, H., Ramachandran, C., Melnick, S. J., Imai, A., Fife, R. S., Carr,

R. E., Oikawa, T., Lansky, E. P. 2003. Preliminary studies on the anti-angiogenic potential of pomegranate fractions in vitro and in vivo. Angiogenesis, 6, 121-

128. http://dx.doi.org/10.1023/b:agen.0000011802.81320.e4 